\title{
Feasibility study of using integrated fiber optical sensors to monitor laser-assisted metal-polymer joining
}

\author{
K. Schricker ${ }^{1}$ (D) - M. Gan $\aleph^{2}$ • C. Könke ${ }^{2}$ J. P. Bergmann ${ }^{1}$ \\ Received: 15 November 2019 / Accepted: 15 June 2020 / Published online: 24 June 2020 \\ (C) The Author(s) 2020
}

\begin{abstract}
The possibilities and challenges of using fiber optical sensors to monitor the laser-assisted joining of metal-polymer joints have been described in this article. Fundamental investigation proves the basic suitability of the measuring method for this application and studies the effect of essential influencing variables of the joining process — e.g., the clamping force — on the resulting sensor signals. In addition, the strain state (because of the process temperature and shrinkage of the polymer) of the parts to be joined can be traced as a function of the joining partners, the process parameters, and the material thicknesses. It is shown that the fiber optical method is suitable for process monitoring directly in the joining zone of metal-polymer hybrids and providing a tool for detailed strain measurements in the joint zone during subsequent component testing.
\end{abstract}

Keywords Laser welding $\cdot$ Hybrid welding $\cdot$ Dissimilar materials $\cdot$ Plastics $\cdot$ Structural analysis

\section{Introduction and state of the art}

The use of the right material at the right place plays a leading role in actual design approaches. The realization of multimaterial components depends strongly on the joining technology as a key manufacturing process, especially for materials with dissimilar properties such as metals and polymers. Therefore, thermal joining is a potential technology for manufacturing thermoplastic-metal joints without using a filler material (e.g., adhesive) or a joining element (e.g., screw, rivet). In thermal joining, both materials are in contact at the boundary layer (Fig. 1a) and the metal sheet is heated by an energy source like a laser beam. A laser-based process has advantages over alternative energy carriers due to the noncontact energy input and the flexibility for joining different

Recommended for publication by Commission XVI - Polymer Joining and Adhesive Technology

K. Schricker

klaus.schricker@tu-ilmenau.de

1 Production Technology Group, Technische Universität Ilmenau, Ilmenau, Germany

2 Institute of Material Research and Testing (MFPA), Institute of Structural Mechanics, Bauhaus University Weimar, Weimar, Germany geometries with the same setup. The metal sheet is heated based on the energy input, and the polymer melts due to the heat transfer between both materials. The molten polymer then penetrates the previously created structures of the metal and wets the surface (Fig. 1b). A solid joint is formed after solidification of the polymer based on mechanical interlocking and physico-chemical interactions (Fig. 1c).

Hybrid metal-polymer structures have been investigated regarding different aspects. On the one hand, destructive testing was carried out in several ways - e.g., tensile test, tensileshear test, or thermal cycling test $[5,7]$. Since $100 \%$ inspection of all finished parts is not possible, the field of nondestructive test methods is increasing. Several approaches are described in the literature - e.g., ultrasonic inspection, optical coherence tomography, x-ray imaging, or thermography $[9,10,21]$. Any test of the finished part involving the abovementioned or other methods has the following disadvantage: the test can only be applied during or after joining the components. An overarching technology of non-destructive testing, which offers data acquisition during the joining process and the lifecycle, has not been described yet. However, the application of fiber optical sensors in the joining zone may fulfill these requirements.

Very thin fiber optical sensors, such as fiber Bragg grating sensors (FBGs), allow the measurement of the changes caused by temperature and mechanical strain. Owing to their insensitivity to electromagnetic interference, their corrosion 
Fig. 1 Principle of laser-based thermal joining

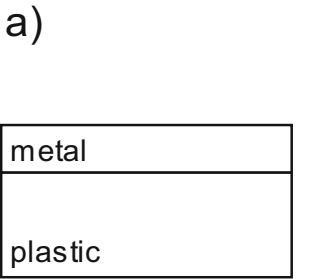

initial situation

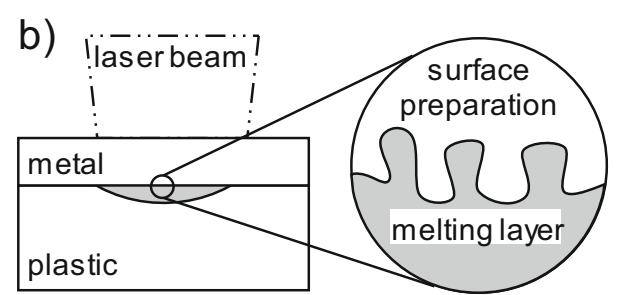

during energy input c)

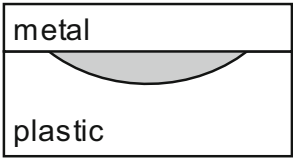

after solidification resistance, and their longtime stability, FBGs are widely used for structural monitoring for various applications [17, 20, 26]. FBGs are light-guiding optical fibers with zones where the index of refraction in the fiber core is modulated periodically. The zones with changed optical properties are the so-called Bragg gratings [16]. When broadband light is passed through the fiber Bragg grating (FBG), a wavelength-selective reflection of the light occurs, as shown schematically in Fig. 2. The light is reflected at the Bragg wavelength $\lambda_{\mathrm{B}}[16]$.

If the temperature or mechanical strain along the fiber axis is applied to the fiber Bragg grating, the Bragg wavelength is shifted to lower or higher wavelengths depending on the situation. The Bragg wavelength shift is expressed as:

$\frac{\Delta \lambda_{B}}{\lambda_{B}}=(\alpha+\xi) \Delta T+(1-\rho \mathrm{e}) \varepsilon$

with $\Delta \lambda_{\mathrm{B}}$ is the change in the Bragg wavelength, $\rho$ e is the photoelastic constant, $\alpha$ is the thermoelastic coefficient, $\xi$ is the thermo-optic coefficient, $\Delta T$ is the change in temperature, and $\varepsilon$ is the strain. Further information on the relations between the change in optical properties and the temperature and strain are given in [16]. Therefore, the shift of the Bragg wavelength depends on both temperature and mechanical strain. For strain measurements at constant temperatures, the Bragg wavelength peak shift is typically converted into a measure of the strain along the axis of the optical fiber. If the temperature is not constant, the temperature effects must be separated from mechanical strain effects by using temperature compensation techniques. Here, mechanically unstrained FBGs can be used for temperature measurements.

It was shown that FBGs can be used as embedded sensors in laminated composite structures [4] as well as in adhesive layers of structural joints [2]. Embedded FBGs can reveal detailed information on strain or temperature at different points in a structure [15]. Peters et al. show that the complex stress in structures can strongly distort the reflected spectra from a single narrow peak to a broad complex spectrum with multiple peaks for embedded FBGs [14]. The spectral distortion can be attributed to strain gradients, multiple strain states, and inhomogeneities in the strain field along the axis of the FBGs [14]. Stress perpendicular to the fiber axis could further result in some kind of spectral distortion [25]. Thus, it is important for many applications to capture the complete spectral response of the fiber Bragg grating during the measurements.
Fig. 2 Schematic representation of the principle of fiber Bragg grating sensors (a) FBGs with the reflected light spectra

(wavelength at maximum of the peak is the Bragg wavelength $\lambda_{\mathrm{B}}$ ) and (b) shift of the Bragg wavelength $\left(\Delta \lambda_{\mathrm{B}}\right)$ due to change of temperature or/and mechanical strain a)

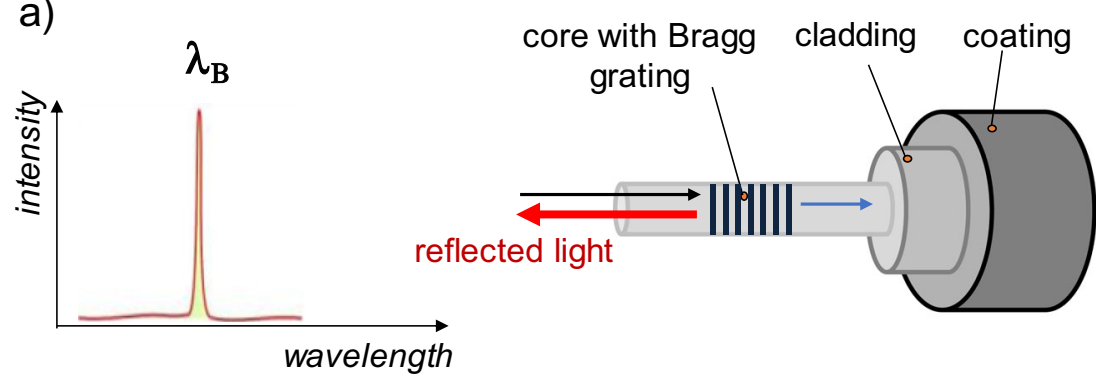

b)

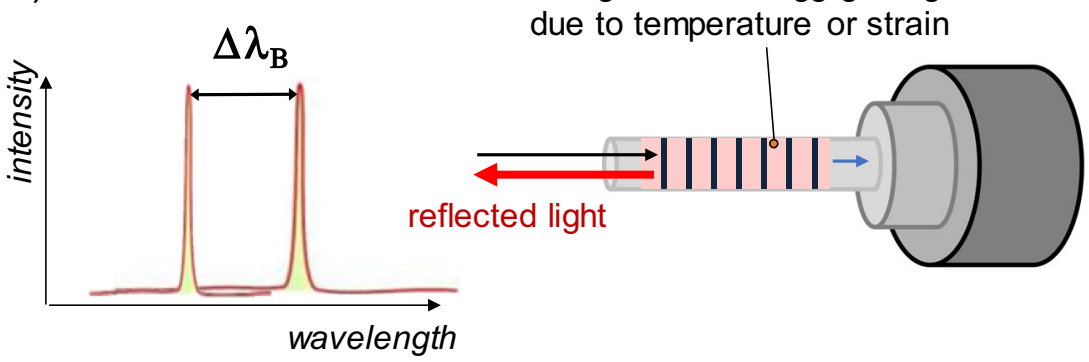


Normally, FBGs are attached to the surfaces of the structure of interest by structural adhesives. Next to adhesive joining, thermal-joining technologies are available to mount FBGs on metal surfaces. Therefore, special FBGs coated with a metallic fiber coating were developed to measure temperatures up to $1000{ }^{\circ} \mathrm{C}$ [24]. The metallic-coated fibers can be soldered or brazed to the surfaces. Special fiber optical sensors coated with metal were successfully embedded in metals by brazing and TIG welding. The embedded sensor showed good response in both strain and temperature after the joining process [3]. Müller et al. observe that by soldering metal-coated FBGs, the spectral response of the fiber Bragg grating change and that wavelength shifts towards shorter wavelengths occur as a result of the strains induced by cooling [13].

However, the use of FBGs for analyzing the thermal processes itself is rare. Few studies describe the possibility of using surface-mounted sensors to analyze thermal-joining processes and to increase the knowledge of the material and the process. Rodriguez-Cobo et al. have used FBGs to perform online detection of defects during arc-welding processes [19]. There the FBGs have been glued to the metal surfacethe researchers have successfully detected the response to the strain and temperature during welding to study their evolution as weld flaws (drop in the welding current, gas shortages) appearing in the process. Moreira et al. have used FBGs for temperature analysis during metal inert gas welding and find a good agreement with thermocouples and the IRthermographic system [12]. Richter-Trummer et al. have used surface-mounted FBGs to analyze transient and residual strains during inert gas and friction stir welding processes. They have discussed monitoring technology in the light of process optimization and subsequent structural health monitoring [18].

There is no state-of-the-art knowledge of investigating the application of embedded fiber optical sensors directly in the process zone in hybrid joints for monitoring the thermal- joining process. Especially for a better understanding of the welding process in metal-polymer hybrids, the use of embedded minimally invasive sensors for the process analysis and quality assurance is a novel approach. By this procedure, information about the hybrid component can be obtained during the joining process as well as during component testing or component deployment.

This article demonstrates the possibilities and challenges of integrating and using fiber optical sensors in the joining zone (Fig. 3) for analyzing the laser-assisted joining of metalpolymer hybrids. A detailed analysis of the spectral response of the embedded Bragg gratings and the evaluability of the resulting signals during initial assembly (Fig. 3a), clamping (Fig. 3b), and the study of the effects of the variables in the joining process (Fig. 3c) were implemented. Based on this, the development of the strain over time (because of the process temperature and shrinkage of the polymer) of the parts to be joined was evaluated as a function of the joining materials, the process parameters, and the material thicknesses used (Fig. 3d). It will be shown that the fiber optical method is in principle suitable for process monitoring directly in the joining zone of metal-polymer hybrids for contour joining as well as simultaneous joining. Nevertheless, the analysis of the resulting FBG signals is still a challenge due to the complexity of the welding process and needs further investigation using detailed process simulations.

\section{Experimental setup}

\subsection{Fiber optical sensors and measuring system}

The fiber optic sensors used in this study are draw-tower fiber Bragg grating sensors with the special Ormocer coating from the FBGS Technology GmbH (DTG LBL-1550, FBGS Technology GmbH, Germany). The draw-tower gratings
Fig. 3 Steps considered for the integration of fiber optical sensors in the metal-polymer joints: sensor application (a), clamping (b), joining process (c), and hybrid component (d) a) initial assembly
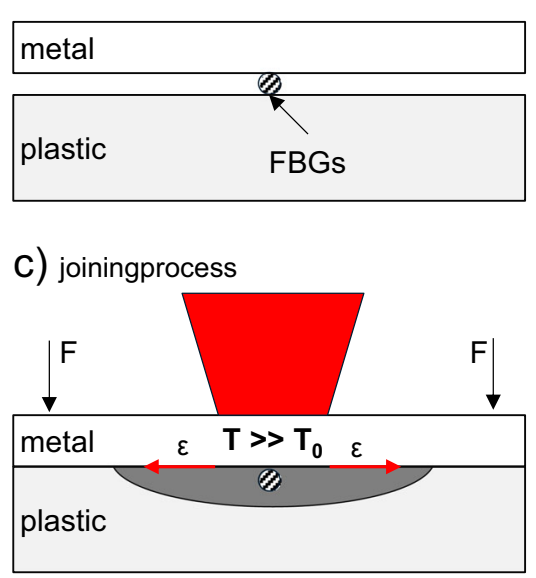

b) clamping

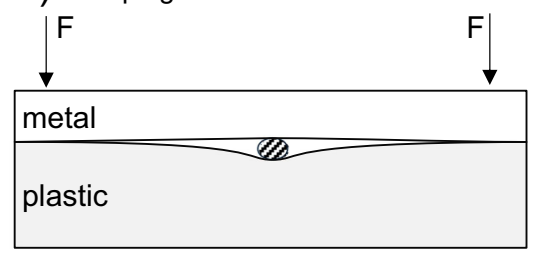

d) hybrid component

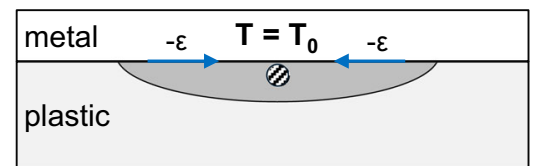


written in low bend loss fiber LBL-1550-125 has a cladding diameter of $125 \mu \mathrm{m}$. The fiber diameter including the coating is $195 \mu \mathrm{m}$. For the investigation, fibers with two fiber Bragg gratings were used with initial Bragg wavelengths of 1535 and $1555 \mathrm{~nm}$. Each of the FBGs is $8 \mathrm{~mm}$ wide and shows a reflectivity of more than $30 \%$. The FBGs with the Ormocer coating are stable in the long term at $200{ }^{\circ} \mathrm{C}$ and can be used for short times at temperatures around $400{ }^{\circ} \mathrm{C}[1,11]$.

The FBGs were selectively fixed on the polymer plate surface and slightly pre-stretched using a special UV-curing adhesive. Afterward, the metal plate was placed on the polymer and fixed with adhesive tape outside the processing zone. After placing the sample in the welding equipment, the Bragg wavelength observed was set as the initial wavelength.

For analyzing the full-spectral response in reflection, a fiber Bragg grating measuring system from AOS (AOS GmbH, Germany), comprising a CCD spectrometer with four input channels and a working wavelength range of $1515-1570 \mathrm{~nm}$, was used in this study. A schematic representation of the measuring system is shown in Fig. 4.

Initially, the spectrum of the reflected light was recorded to analyze the influence of clamping force and welding energy on the spectral response of the FBGs. In further investigation, the change in the peak wavelength to the initial Bragg peak wavelength was analyzed. The peak wavelength of the spectrum was estimated by fitting it with the Gauß function. The peak wavelength of the FBGs, after fixing the geometry in the weld fixture, is the reference value $\left(\lambda_{\mathrm{B} 0 \text { _FBG }}, \Delta \lambda_{\mathrm{B}_{-} \mathrm{FBG}}=0\right)$. The peak wavelength shift $\Delta \lambda_{\mathrm{B}}$ was calculated with regard to $\lambda_{\mathrm{B} 0_{F} \mathrm{FBG}}$.

For the test of the applicability of the fiber Bragg grating approach for simultaneous welding, one FBGs having three Bragg gratings with corresponding wavelengths of 1530 , 1540 , and $1550 \mathrm{~nm}$ were used, respectively. The change in the wavelength was recorded simultaneously for the three different conditions (see Sect. 2.2).

The applicability of bare FBGs was proved before metalpolymer hybrids with the embedded sensors were realized.
Therefore, the bare, unstrained FBGs were placed in an oven and the sensor signal was measured while heating them up until approx. $400{ }^{\circ} \mathrm{C}$ - this typically represents a range of maximum temperatures in the joining process. The temperature was calculated from the wavelength shift using the temperature-sensitivity coefficient of $6.5 \mathrm{~K}^{-1} \cdot 10^{-6}$ [1]. Parallel to this, the temperature in the oven was measured close to the FBGs using a thermocouple type $\mathrm{K}$ and an Almemo-measurements system (Ahlborn Mess- und Regelungstechnik $\mathrm{GmbH}$ ). Figure 5a compares the two measured temperatures of the thermocouple and the FBG. The temperature-temperature plot shows a good linear relation between the temperature values from the FBGs and the temperature from the thermocouple. However, the long-term exposure (few minutes) at a temperature around $400{ }^{\circ} \mathrm{C}$ in the oven resulted in a degradation of the Bragg grating and hence a significant loss of spectral intensity. The phenomenon of degradation was already discussed in the work of Lindner [11]. It was shown that the Bragg grating degradation is a function of the grating type, the temperature, and also depends strongly on the time of exposure. For temperatures above $700{ }^{\circ} \mathrm{C}$, no significant reduction of the spectral response occurred for short times (a few seconds), whereas long dwell times (a few minutes) at this temperature led to a strong degradation and spectral intensity. This illustrates that the conditions in an oven experiment over long periods of time cannot be directly compared with the short-term temperature load in the thermal-joining process. In order to verify the observation of [11] for the following investigations in thermal joining, the temperature load of the FBGs in the joining process was simulated by a short-term heating of up to $500{ }^{\circ} \mathrm{C}$ using a hot airsoldering system. After cooling down to room temperature, the spectral response with intensity and initial Bragg wavelength were comparable with the initial spectrum. A significant degradation of the FBG was not evident. In all following investigations regarding laser-assisted metal-polymer joining, the FBG spectrum was measured successfully, indicating that
Fig. 4 Schematic of the fiber Bragg grating measuring system

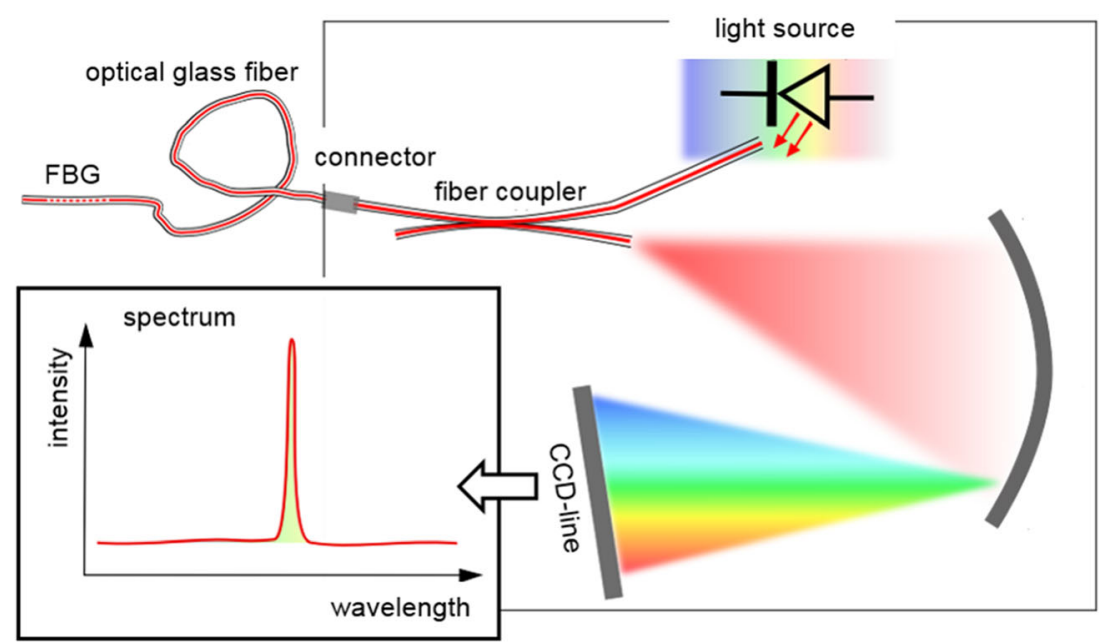


Fig. 5 Characteristics of the FBGs: a temperature-temperature plot showing the linear relation between FBGs and thermocouple from an oven experiment and $\mathbf{b}$ spectral response of the bare FBGs before and after joining for simultaneous welding a) comparison of measured between thermocouple and FBG

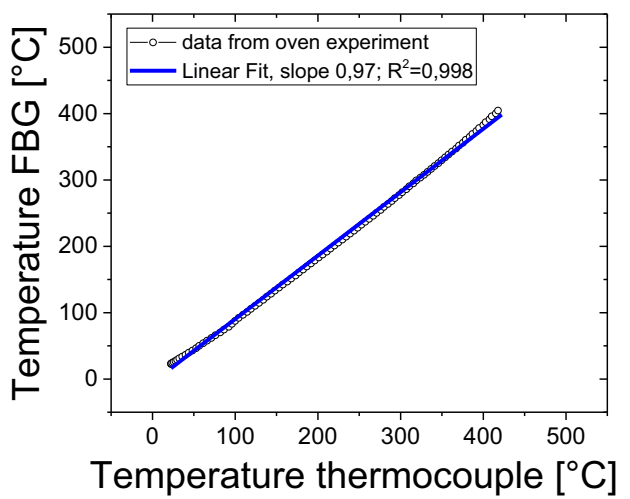

b) spectral response of bare FBGs before and after joining

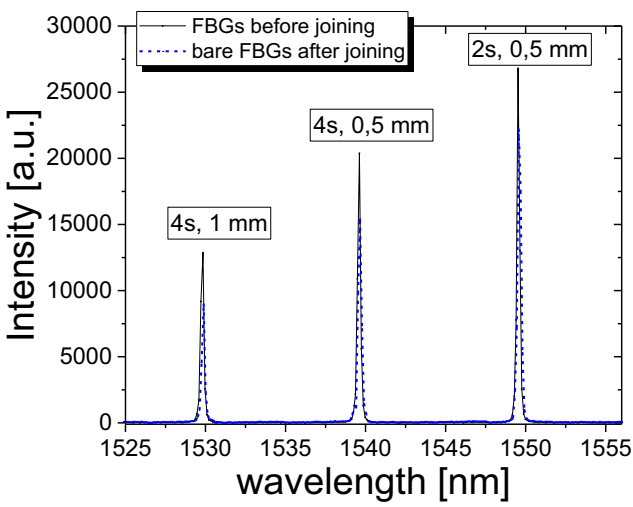

the short-term temperature load does not result in a strong Bragg grating degradation. Figure $5 \mathrm{~b}$ compares the spectral response of the FBGs before and after the simultaneous joining process at different joining times, which also result in different maximum temperatures. For this purpose, the joint was carefully separated by detaching the polymer plate from the metal with a load perpendicular to the weld plane and a slight heat input with temperatures above the glass transition of the used polymers. Subsequently, the sensor signal of the FBGs was measured and a slight reduction in the intensity of the peak can be observed. However, the slight reduction of the spectrum intensity does not affect the evaluation of the sensor signal and is possibly due to a slight degradation of the FBG. A change of the fiber coating or brown coloring was not observed and subsequently the joining process was investigated using FBGs. The influence of the joining process on the FBGs' spectrum is studied in Sect. 3.1.

\subsection{Laser-based metal-polymer joining}

The experimental setup is given in Fig. 6. The heat conduction joining process was carried out with a Laserline LDM 3000 diode laser $\left(\lambda=980 \mathrm{~nm}, P_{\mathrm{L}, \max }=3000 \mathrm{~W}\right)$ as contour joining as well as simultaneous joining. The clamping device was used for both joining strategies; it allows the adjustment of the clamping force due to integrated load cells. For a generalization of the results, a comparison of the effects is made based on the energy per unit length $\left(E_{\mathrm{CW}}\right)$ for contour and energy input $\left(E_{\mathrm{S}}\right)$ for simultaneous welding. Both joining strategies are industrially relevant and used depending on the metal material. In aircraft or vehicle construction, aluminum alloys with greater material thicknesses $(t=1 \ldots 3 \mathrm{~mm})$ are used, which is why a high-energy input is required. Owing to this fact, these alloys are mainly welded using the contour process. On the other hand, steels are predominantly used with lower material thicknesses-e.g., in household appliance technology $(t=0.3 \quad \ldots \quad 0.8 \mathrm{~mm})$ —and can be processed in simultaneous welding due to their significantly lower thermal conductivity and comparably higher degree of absorption.

In contour welding, a focal diameter of $5.3 \mathrm{~mm}$ was chosen with welding speeds from $2.5 \mathrm{~mm} / \mathrm{s}\left(E_{\mathrm{CW}}=400 \mathrm{~kJ} / \mathrm{m}\right.$ with laser beam power $\left.P_{\mathrm{L}}=1000 \mathrm{~W}\right)$ to $5 \mathrm{~mm} / \mathrm{s}\left(E_{\mathrm{CW}}=200 \mathrm{~kJ} / \mathrm{m}\right.$ with $\left.P_{\mathrm{L}}=1000 \mathrm{~W}\right)$. The welding speeds were selected based on preliminary investigations (see [23]) to ensure a connection of both joining partners in the entire overlap area. Natural polyamide 6 (PA6, $\left.t_{\mathrm{P}}=2 \mathrm{~mm}\right)$, natural polypropylene (PP, $\left.t_{\mathrm{P}}=2 \mathrm{~mm}\right)$, and aluminum EN AW $6082\left(t_{\mathrm{M}}=1.5 \mathrm{~mm}\right)$ were selected as materials due to their high application relevance. Clamping forces $(F)$ of 500 and $1000 \mathrm{~N}$ were investigated to determine the effect on the fiber optical sensors. The joint configuration of contour welding is shown in Fig. 7a.

In simultaneous welding, a rectangular laser beam focus with the dimensions of $18.3 \mathrm{~mm}^{2}$ was chosen. Natural polypropylene (PP, $t_{\mathrm{P}}=2 \mathrm{~mm}$ ) and highalloyed steel (1.4301/AISI 304/X5CrNi18-10, $t_{\mathrm{M}}=$ $0.5 \mathrm{~mm}$ ) were used as joining partners to address the

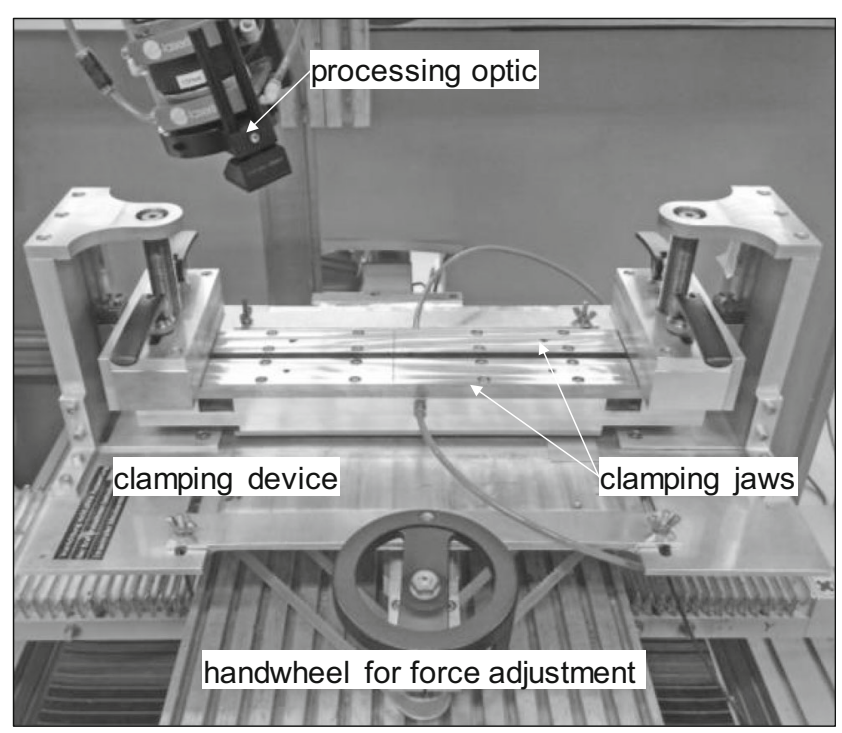

Fig. 6 Experimental setup for laser-based joining 
a) contour welding

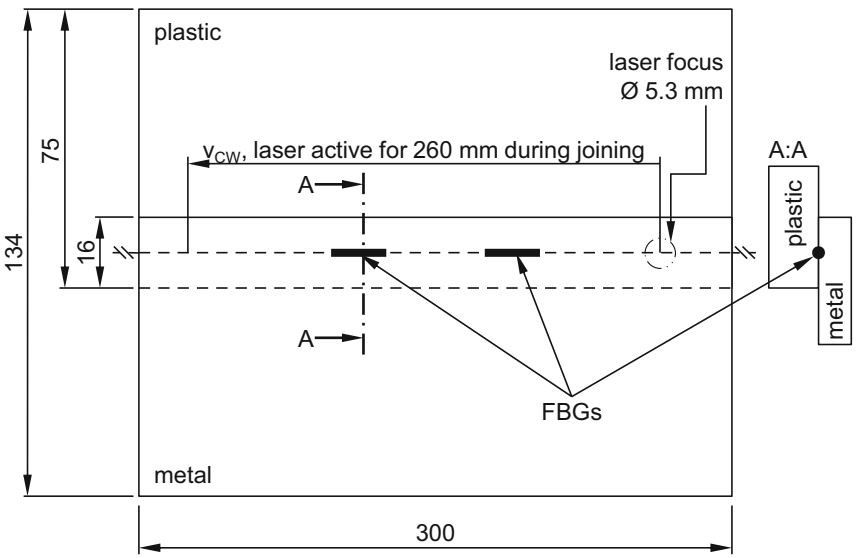

b) simultaneous welding

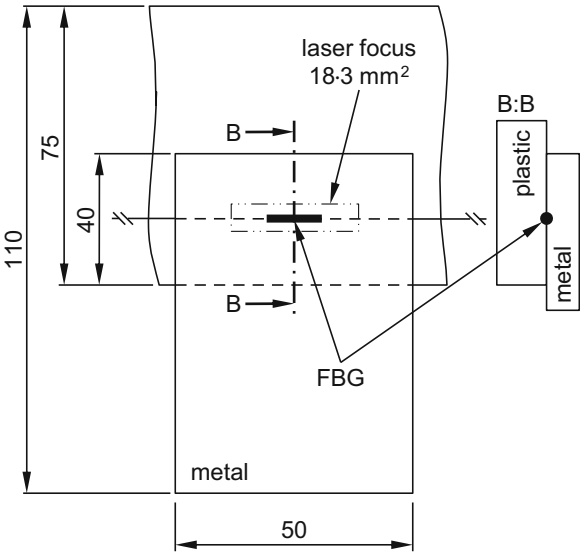

Fig. 7 Joint configuration with sensor position in a contour welding and $\mathbf{b}$ simultaneous welding

requirements of household appliance technology. The joining parameters were chosen based on preliminary investigations $\left(P_{\mathrm{L}}=150 \mathrm{~W}\right.$, joining time $\left.t_{\mathrm{L}}=2 \ldots 4 \mathrm{~s}\right)$. A constant clamping force of $500 \mathrm{~N}$ was chosen. The joint configuration of simultaneous welding is given in Fig. $7 b$.

The number of the sensors and the position were changed along the drawn line during the experiments. The actual position of the fiber optical sensors is given in the corresponding diagrams and results.

In all cases, the metal surface was initially processed with laser radiation with a fiber laser (Rofin PowerLine F20, $\lambda=1070 \mathrm{~nm}$ ). The surface profile after the pretreatment of both materials is given in Fig. 8a, and the parameters are listed in Table 1. The diameter of the fiber optical sensor $\left(\varnothing_{\mathrm{FBGs}}\right)$ extends over to two to three grooves. The groove-shaped structures are very evenly formed - this was verified by $3 \mathrm{D}$ measurements using a laser-scanning microscope (Olympus LEXT 4000 ) and is given for 1.4301 in Fig. 8b. Although the achievable joint strength is not the focus of this article, such surface structures are used in the applications addressed. At the interface, they are in direct contact with the fiber optical sensor and therefore also considered in the investigations.

\section{Results and discussion}

It is very desirable to analyze the metal-polymer joints during the thermal-joining process, as mentioned above. In the weld zone, integrated sensors can provide a detailed process understanding for the optimization and sensor data for monitoring as well as for nondestructive testing during the product lifecycle. The experimental results and discussion from measurements with FBGs integrated in the process zone of the metal-polymer hybrid joints are given below. The principal analysis of the influence of clamping force for contour welding on the spectral response of the FBGs was explored (Sect. 3.1) for PA6. After understanding the effect of the clamping force, fiber Bragg grating measurements with different polymer materials (i.e., PP and PA6) and different welding energies for contour welding are discussed in Sect. 3.2. To address different cases, the sensor method was tested for the

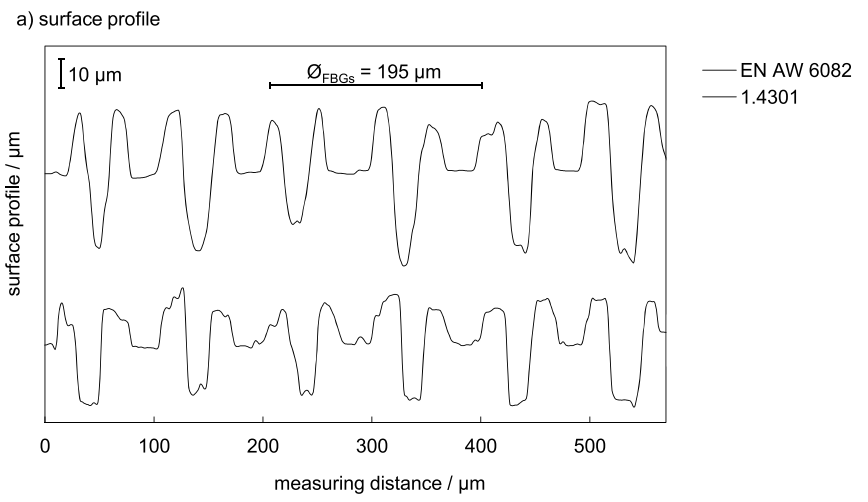

b) 3D measurement of surface (1.4301)

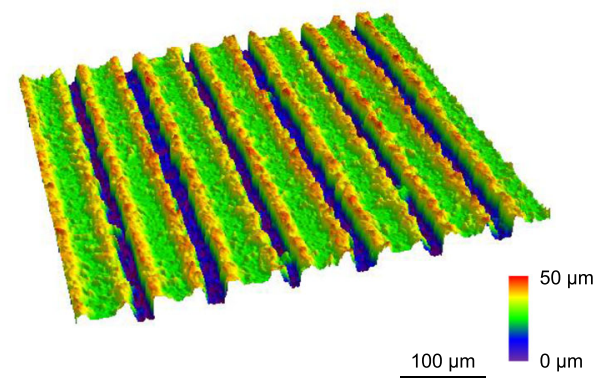

Fig. 8 a Surface profile for aluminum EN AW 6082 and high alloyed steel (1.4301); b 3D measurement of the surface (1.4301) 
Table 1 Process parameter for the surface preparation

\begin{tabular}{|c|c|c|}
\hline Parameter & EN AW 6082 & 1.4301 \\
\hline Average laser beam power (W) & 20 & 18 \\
\hline Pulse frequency $(\mathrm{kHz})$ & 50 & 60 \\
\hline Velocity $\left(\mathrm{mm} \mathrm{s}^{-1}\right)$ & 200 & 200 \\
\hline Number of passes (1) & 1 & 1 \\
\hline Structure shape & Line & Line \\
\hline
\end{tabular}

simultaneous welding process at different welding parameters and material thicknesses.

\subsection{Preliminary investigations of the influence of clamping force in contour welding on the FBGs response}

The use of FBGs in general allows the analysis of temperatures and strains locally near the Bragg grating. Temperature and strain changes are indicated by a shift of the Bragg spectrum. Conversely, temperatures and strains can be directly calculated using specific constants of the optical fibers by measuring the shift of the Bragg wavelength.

In the first step, the energy per unit length and the clamping force were varied. Before the effects are discussed individually below, the overarching effects will be described. It can be seen in Fig. 9a-c for all process configurations that the welding process results in a strong shift of the peak wavelength in the fiber Bragg grating spectrum to higher peak wavelengths. The strong shift of the peak wavelength in the spectrum to higher peak wavelengths comes from the temperature and temperature-induced strains due to the heat input by the laser spot through the metal plate. After reaching the maximum, the peak wavelength of the spectrum is shifted backwards to the initial Bragg peak wavelength $\Delta \lambda_{\mathrm{B} 0}$ and below due to the cooling down to room temperature after the laser beam has been switched off. In the 2D data of Fig. 9a-c, it is clearly observable for all process conditions that the peak wavelength of the spectrum shifts to lower wavelengths than the initial wavelength $\left(\Delta \lambda_{\mathrm{B}_{-} 0}\right.$ corresponds to room temperature). This phenomenon was also observed for composite materials [8], where it was demonstrated that FBGs offer significant potential for measuring the residual strains within composite materials and fiber metal laminates. Thus, the significant shift in the peak wavelength after processing provides a useful indication of the residual strain in the joints. The mismatch in the coefficients of thermal expansion and the shrinkage of the polymer leads to the generation of compressive strains around the FBGs when the samples are cooled down from elevated temperatures. The process characteristics and change of Bragg peak wavelength will be discussed in detail in Sect. 3.2 for different materials.
In addition to the spectrum shift, a distortion of the spectrum-i.e., a reduction of the spectral peak height, broadening, and peak splitting - is observable in the FBGs' data, as shown in the 2D representation in Fig. 9a-c. In the investigated joining process, the clamping force and the energy per unit length can induce transversal stress to the fiber optical sensors (stress perpendicular to optical fiber axis), thus resulting in a complex spectral response. As shown for the FBGs embedded in composites, the transversal stress can lead to distortion or broadening of the spectrum, existence of multiple peaks, and a reduction in the reflected light intensity. The influence of such transversal stresses, mainly induced by the clamping force and the joining process here, was studied by varying the clamping force. The change in the reflected spectra with the application of the clamping force and during the welding process is depicted in Fig. 9a-c for the samples welded with the clamping forces of 1000 and $500 \mathrm{~N}$ and the welding energies of 200 and $400 \mathrm{~kJ} / \mathrm{m}$. The effect of clamping force on spectrum distortion becomes clearly visible by comparing Fig. 9a with Fig. 9b. In the plots, the time of clamping is marked with an arrow in the figures with 3D data and shown for simplicity in the $2 \mathrm{D}$ plot with the intensity versus the wavelength. It is clearly visible from the graphs that any reduction in the clamping force from 1000 to $500 \mathrm{~N}$ results in a Gauß-shaped peak with high intensity, whereas at $1000 \mathrm{~N}$, the spectrum is distorted with loss in intensity, caused by the higher transversal stress induced. By reducing the clamping force to $500 \mathrm{~N}$, the peak splitting becomes absent- this facilitates the evaluation of the spectral shift. A further reduction of the clamping force as well as the welding energy during the investigations led to a less distorted spectra with nearly the same peak intensity as in the initial state (results are not shown here). However, the reduced clamping force led to a poorer contact between metal and polymer, resulting in an insufficient connection between both materials.

Furthermore, a reduction in the process energy per unit length to $200 \mathrm{~kJ} / \mathrm{m}$ in Fig. 9c at constant clamping conditions results in a higher spectral peak compared with the samples welded at $400 \mathrm{~kJ} / \mathrm{m}$ with the same clamping force. The increased energy input at $400 \mathrm{~kJ} / \mathrm{m}$ leads to a stronger penetration of the metal into the polymer part, as already discussed in [23], and can simultaneously lead to an increased level of transversal stress in the process zone of the joint. Consequently, the spectral response of the FBGs is affected. It should be mentioned that concurrent to the spectrum distortion induced by transversal stress, the local heat input may result in short-term broadening and splitting of the spectrum due the small laser spot size and thereby induce the inhomogeneous strain field, especially when the laser spot crosses the Bragg grating directly during the contour-welding process. However, the major influence on the fiber Bragg grating spectral response-i.e., the wavelength shift - results from temperatures, thermally induced strains and residual strains due 
Fig. 9 Spectral response of the FBGs in the joining zone during welding a $1 \mathrm{FBG}$ at $E_{\mathrm{CW}}=$ $400 \mathrm{~kJ} / \mathrm{m}$ and $F=1000 \mathrm{~N}, \mathbf{b} 2$ FBG at $E_{\mathrm{CW}}=400 \mathrm{~kJ} / \mathrm{m}$ and $F=$ $500 \mathrm{~N}$, and $\mathbf{c} 2 \mathrm{FBG}$ at $E_{\mathrm{CW}}=$ $200 \mathrm{~kJ} / \mathrm{m}$ and $F=500 \mathrm{~N}$. (under plots with $3 \mathrm{D}$-data are characteristic 2D-plots of the intensity as function of the wavelength for the specific events)

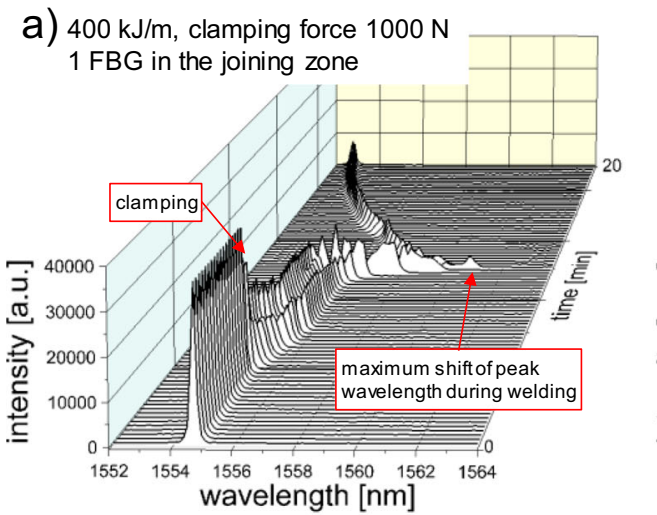

b) $400 \mathrm{~kJ} / \mathrm{m}$, clamping force $500 \mathrm{~N}$
$2 \mathrm{FBG}$ in the joining zone
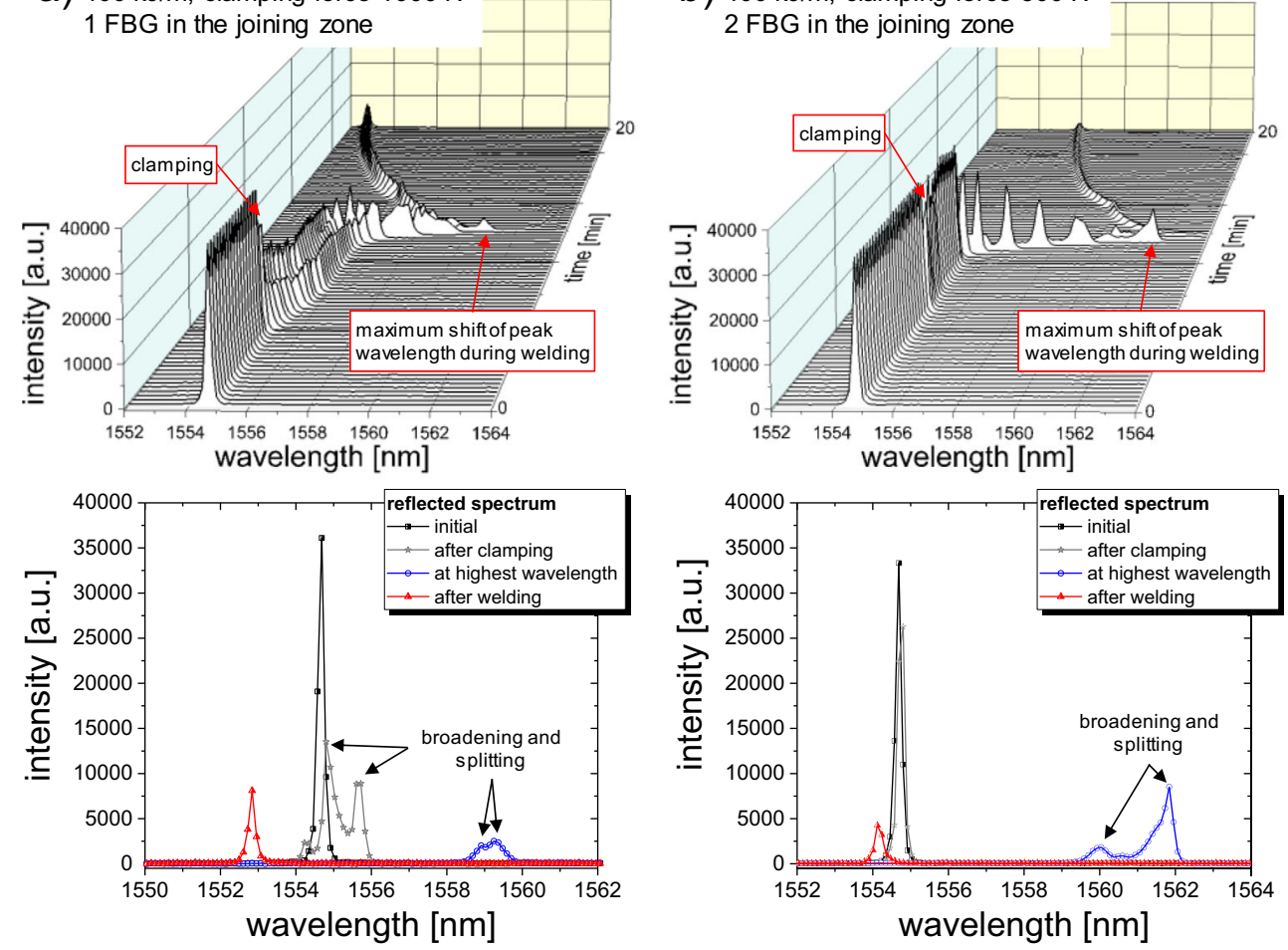

C) $200 \mathrm{~kJ} / \mathrm{m}$, clamping force $500 \mathrm{~N}$ $2 \mathrm{FBG}$ in the joining zone
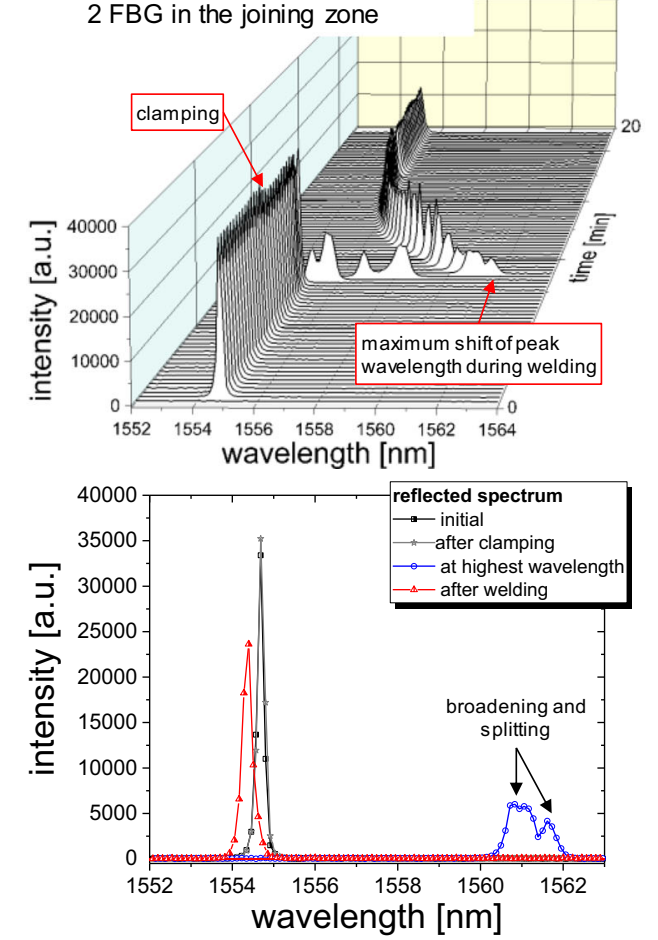

the shrinkage of the polymer, and the mismatch in the coefficients of thermal expansion. These will be further discussed in the next sections.

In addition, microsections were performed to investigate the influence of the fiber optical sensor in the joining zone, as this could have a negative effect on the joint due to the gap introduced. Therefore, after the joining, microsections were prepared from the metal-polymer joint of PA6 and PP for the process energies of $E_{\mathrm{CW}}=400 \mathrm{~kJ} / \mathrm{m}$ and clamping force $F=500 \mathrm{~N}$ and analyzed using light microscopy. The images 
a) PA $6\left(E_{C W}=400 \mathrm{~kJ} / \mathrm{m}, \mathrm{F}=500 \mathrm{~N}\right)$

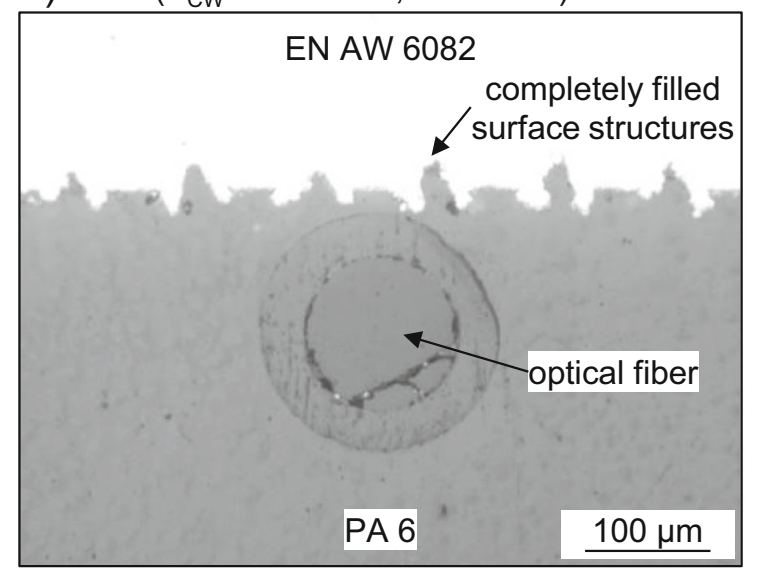

b) $P P\left(E_{\mathrm{cW}}=400 \mathrm{~kJ} / \mathrm{m}, \mathrm{F}=500 \mathrm{~N}\right)$

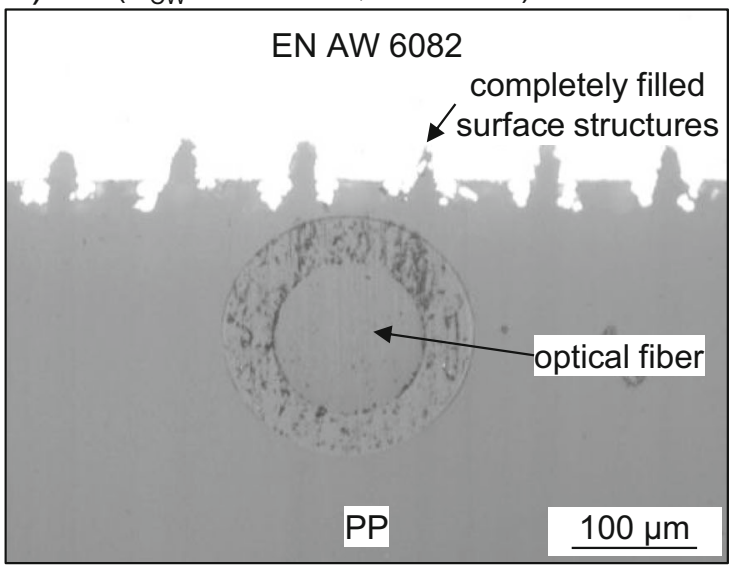

Fig. 10 Microsections from light microscopy (contrast edited): a PA6, $E_{\mathrm{CW}}=400 \mathrm{~kJ} / \mathrm{m}$ and $F=500 \mathrm{~N}$ and $\mathbf{b} \mathrm{PP}, E_{\mathrm{CW}}=400 \mathrm{~kJ} / \mathrm{m}$ and $F=500 \mathrm{~N}$

in Fig. 10 demonstrate that the optical fiber is nicely embedded in the polymer material, and the metal surface was penetrated completely with that material. The melt flow into the microstructure is not hindered by the fiber sensor even at reduced clamping forces of $500 \mathrm{~N}$, indicating that the laserassisted metal-polymer joining process is not significantly affected by the embedded fiber sensor.

The investigations carried out in Sect. 3.1 demonstrate that the integration of FBGs into the joining zone of a laserassisted metal-polymer-joining process is possible without significantly influencing the polymer melt flow into the microstructures. The process temperature and strain during the thermal-joining process leads to a significant Bragg peak wavelength shift of the FBGs to higher wavelengths. After cooling to room temperature, the peak wavelength is shifted to lower wavelengths compared with the initial Bragg peak wavelength, indicating residual strains in the joint. In addition to a wavelength shift due to temperature and temperatureinduced strains, a spectral distortion occurs due the transversal stress induced by the clamping and the joining process itself. By reducing the clamping force and the accompanying transversal stress, the spectral distortion is reduced as well, thus simplifying the evaluation of the sensor signal. Based on these findings, the wavelength shift is further evaluated in Sect. 3.2 for different energies per unit length and polymer materials.

\subsection{Effect of energy per unit length in contour welding}

The influence of the processing parameters and the polymer material on the temperature and temperature-induced strains were further analyzed by evaluation of the Bragg wavelength shift $\Delta \lambda_{\mathrm{B}}$.

The graphs in Fig. 11 show the peak wavelength shift $\Delta \lambda_{\mathrm{B}}$ for FBG1 and FBG2 as a function of time during the contour welding of PP (Fig. 11a) and PA6 (Fig. 11b) with different welding energies of 200 and $400 \mathrm{~kJ} / \mathrm{m}$, respectively. The change of $\Delta \lambda_{\mathrm{B}}$ during the process can be directly correlated with the typical weld procedure. The specific events in the weld process are marked with arrows in the graph for PP, which was welded with an energy per unit length of $200 \mathrm{~kJ} /$ $\mathrm{m}$. After placing the same with FBGs in the clamping device, the fiber Bragg grating measurement started. The peak wavelength is set as the initial peak wavelength $\left(\lambda_{\mathrm{B} 0 \_ \text {FBG1 }}\right.$ and $\left.\lambda_{\mathrm{B} 0 \text { FBG2 }}\right)$. Subsequently, the clamping force is applied to the sample - this is indicated by a small step in the $\Delta \lambda_{\mathrm{B}}$ time curves. The laser spot is located near the right edge of geometry, switched on, and then moved through the sample passing first FBG1 and then FBG2. Because of the energy input from the laser to the metal, the temperature in the process zone and on the polymer plate increases. Hence, the $\Delta \lambda_{\mathrm{B}}$ increases until a maximum is reached. FBG1 is closer to the starting point of the laser and is therefore sooner reached by the laser spot than FBG2 (for details of the sensor position, see Fig. 6). This explains the time shift of the $\Delta \lambda_{\mathrm{B}}$ time curves as well as the shift in the maximum peak wavelength of FBG1 and FBG2. After passing the FBG2, the laser spot moves further and is switched off at a certain point. The switching off is indicated by a slight reduction in $\Delta \lambda_{\mathrm{B}}$ especially observed by FBG2. In the further process, the joint slowly cools to room temperature - this is visible by a gradual reduction of $\Delta \lambda_{\mathrm{B}}$. As discussed in Sect. 3.1, the shift of the peak wavelength to a lower wavelength than the initial peak wavelength $\lambda_{\mathrm{B} 0}$ indicates the occurrence of residual strains. Figure 12 shows the spectral response for and after the welding process (cooled to room temperature) with the characteristic shift of the peak wavelength to a lower peak wavelength than the initial peak wavelength, thereby indicating the occurrence of high residual strains in the welded samples.

The comparison of PA6 (Fig. 11a) and PP (Fig. 11b) for both energies per unit length shows differences in the spectral response and therefore also in the sensor data. The maximum peak wavelength shift, which indicates the maximum temperature in the process, is therefore slightly higher for $400 \mathrm{~kJ} / \mathrm{m}$ 

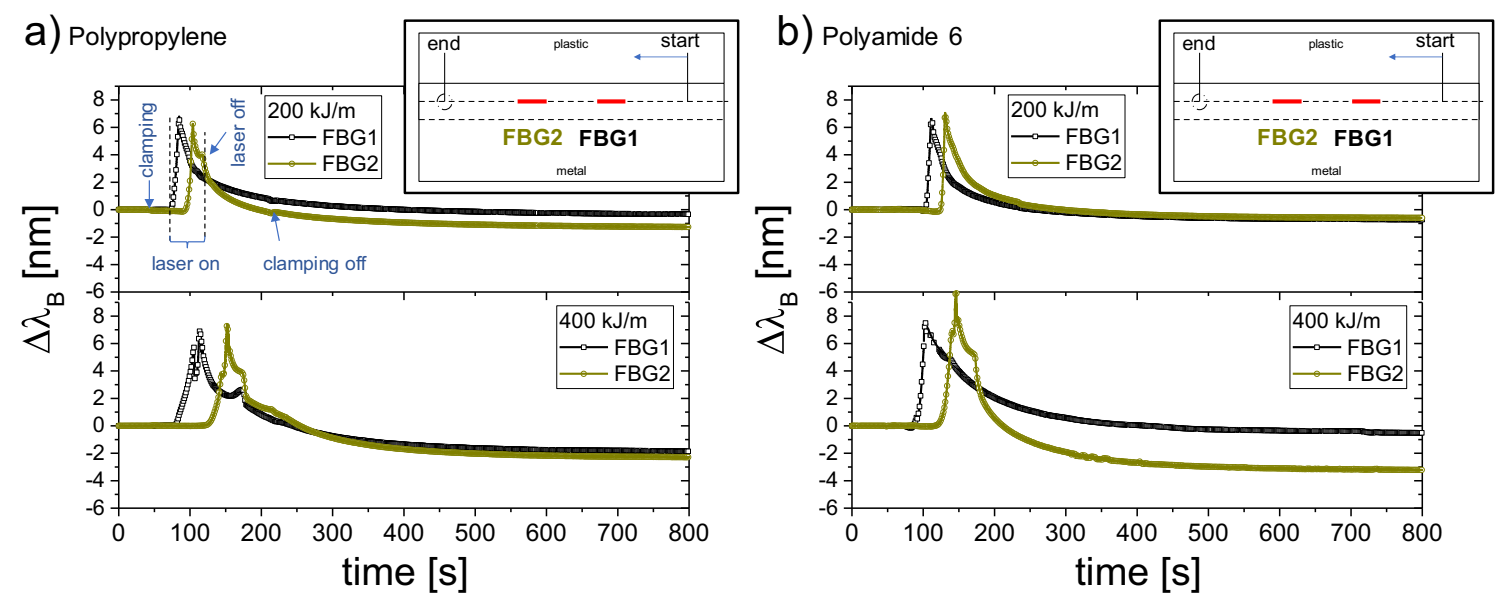

Fig. 11 FBGs data for contour welding - change of the wavelength $\Delta \lambda_{\mathrm{B}}$ as function of the process time till $800 \mathrm{~s}$ (not completely cooled to room temperature) a for PA6 for weld energy at $E_{\mathrm{CW}}=200$ and $E_{\mathrm{CW}}=400 \mathrm{~kJ} / \mathrm{m}$ and b for PP at weld energy of $E_{\mathrm{CW}}=200$ and $E_{\mathrm{CW}}=400 \mathrm{~kJ} / \mathrm{m}$

than for $200 \mathrm{~kJ} / \mathrm{m}$. The width of $\Delta \lambda_{\mathrm{B}}$ during the input of the laser-beam energy is higher for $400 \mathrm{~kJ} / \mathrm{m}$ than $200 \mathrm{~kJ} / \mathrm{m}$ as a logical consequence of the process conditions. In the case of the energy per unit length of $400 \mathrm{~kJ} / \mathrm{m}$, the welding speed is halved from 5 to $2.5 \mathrm{~mm} / \mathrm{s}$. Consequently, the increased energy input of the laser beam leads to higher temperatures and a delayed cooling, as shown in [23]. The energy input of $400 \mathrm{~kJ} /$ $\mathrm{m}$ also leads mostly to a stronger peak wavelength shift of $\Delta \lambda_{\mathrm{B}}$ to shorter wavelengths than the initial peak wavelength of $\lambda_{\mathrm{B} 0}$. This indicates higher residual strains for $400 \mathrm{~kJ} / \mathrm{m}$ than for $200 \mathrm{~kJ} / \mathrm{m}$.

It should be noted that the comparison of the spectral response before and after the welding process further indicates the appearance of higher transversal strains due to a perpendicular stress to the fiber axis for the welding energy of $400 \mathrm{~kJ} / \mathrm{m}$. The reduction of the peak intensity after welding is much stronger (more than five-fold reduction) in the case of the weld energy of $400 \mathrm{~kJ} / \mathrm{m}$ compared with $200 \mathrm{~kJ} / \mathrm{m}$, where only a slight reduction of the peak intensity occurs (approx. 1.4-fold reduction). However, whether this strong change in the peak intensity of the spectrum due to transversal stress correlates with the bonding strength must be analyzed in further studies.

Assuming isothermal conditions after cooling to room temperature, the strain can be calculated from the peaks of the spectra, as shown in Fig. 12, by using the strain gauge factor of $7.8 \mu \varepsilon^{-1} 10^{-7}$ [1] for the fiber optical sensor. Figure 13 shows that for the welding energy of $400 \mathrm{~kJ} / \mathrm{m}$, higher residual
Fig. 12 Spectral response before and after the welding (room temperature): a for PA6 for energies per unit length of 200 and $400 \mathrm{~kJ} / \mathrm{m}$ and $\mathbf{b}$ for PP for weld energies of $E_{\mathrm{cw}}=200 \mathrm{~kJ} / \mathrm{m}$ and $E_{\mathrm{cw}}=400 \mathrm{~kJ} / \mathrm{m}$ a)

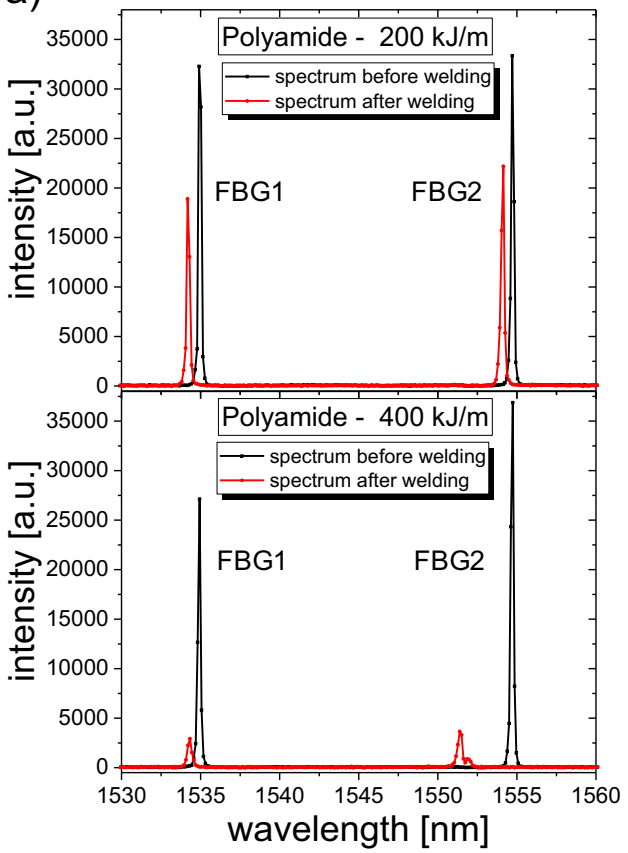

b)

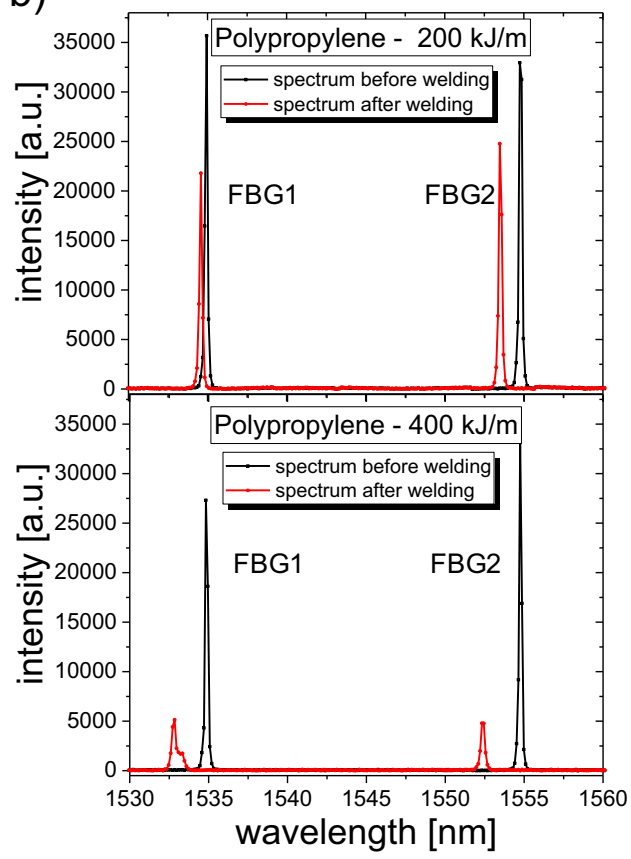




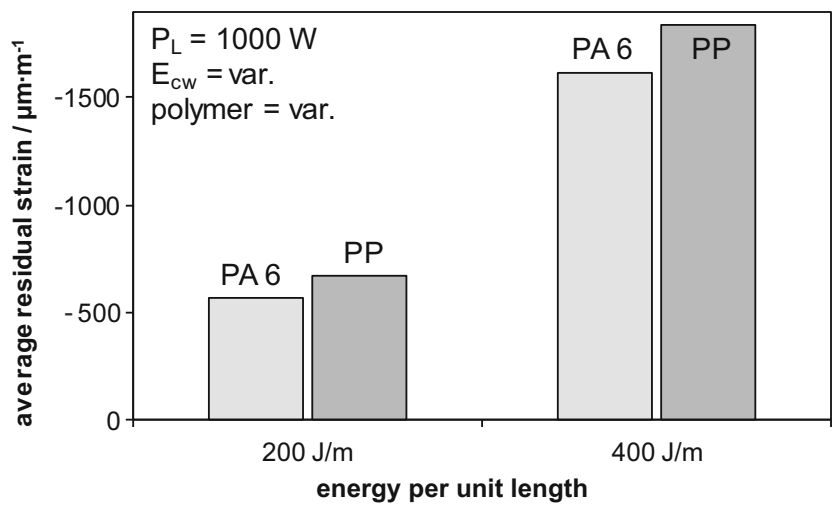

Fig. 13 Residual strains in contour joining calculated from the spectral shift versus polymer and energy per unit length

strains are generally achieved compared with the welding energy of $200 \mathrm{~kJ} / \mathrm{m}$. A possible explanation is the different amounts of the molten material and the melt ejection due to the clamping force at different energies per unit length. At $400 \mathrm{~kJ} / \mathrm{m}$, a much larger amount of polymer is molten - this could result in larger stresses during cooling and solidification due to shrinkage. The comparison of the melt zone thickness between the two polymers supports this assumed influence, since a larger melt zone is achieved for PP in each case. At $200 \mathrm{~kJ} / \mathrm{m}$, for example, a melting layer thickness of $290 \mu \mathrm{m}$ is reached for PP compared with $140 \mu \mathrm{m}$ for PA6. This behavior can be explained by the thermal-physical properties and especially by the melting interval of PP being significantly lower. This also results in different cooling conditions which can affect the resulting residual strains.

\subsection{Investigations of simultaneous welding using FBGs}

In this section, the fiber Bragg grating technique was applied to analyze the simultaneous welding process.

The shift in the wavelength $\Delta \lambda_{\mathrm{B}}$ versus the joining time and different material thicknesses is depicted in Fig. 14a. The typical course of the welding process (heating and cooling), as already discussed in Sect. 3.2, also occurs in the $\Delta \lambda_{\mathrm{B}}$ time curve for simultaneous welding. Temperature simulations (adapted model of [22]) of the welding process, shown in Fig. 14b, are qualitatively in accordance with the $\Delta \lambda_{\mathrm{B}}$ time curve. The increase in the welding time from 2 to $4 \mathrm{~s}$ at a constant metal thickness results in a higher energy input per area and thus in higher maximal temperatures, as indicated by a 2-fold increase in the maximal wavelength shift $\Delta \lambda_{\mathrm{B} \_ \text {Max }}$. The simulation supports the fiber optical results with an increase in the maximum temperature of $100 \mathrm{~K}$ by doubling the joining time. The increase in the metal thickness from 0.5 to a)

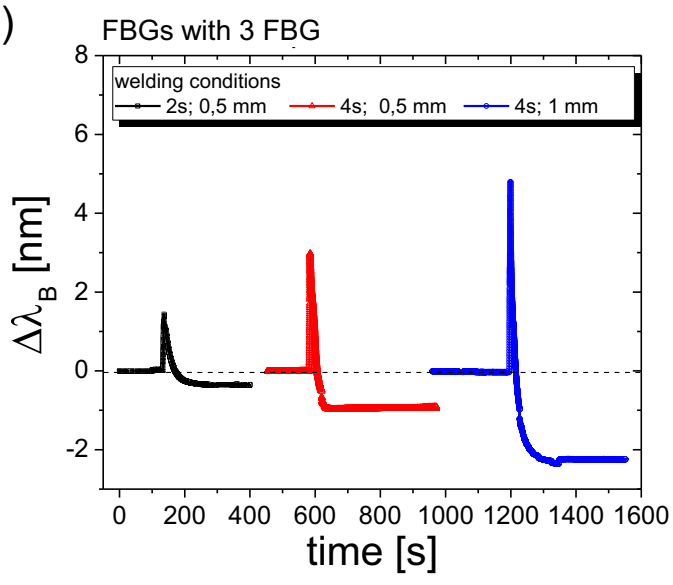

b)

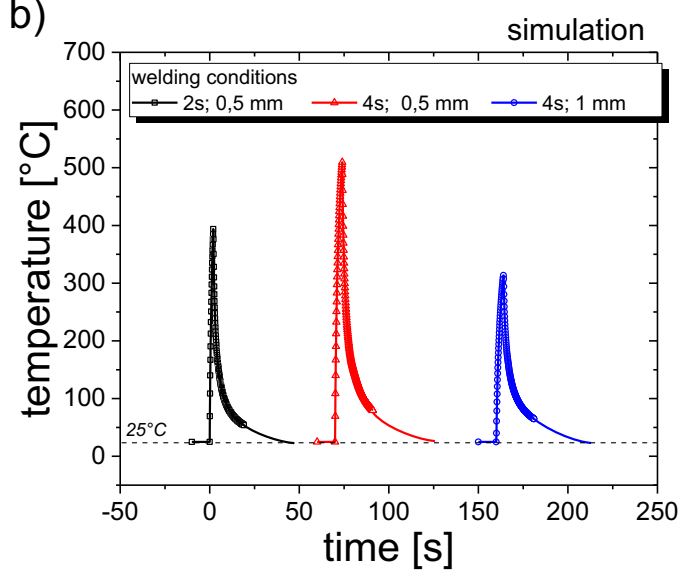

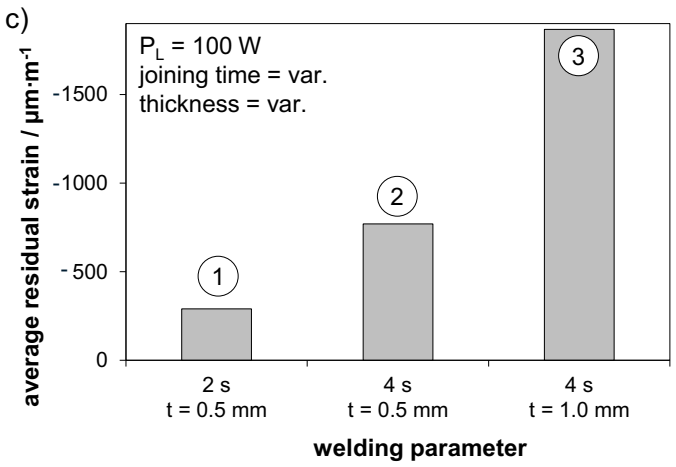

(1)

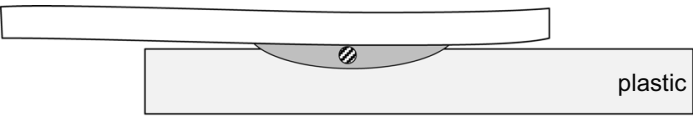

(2)

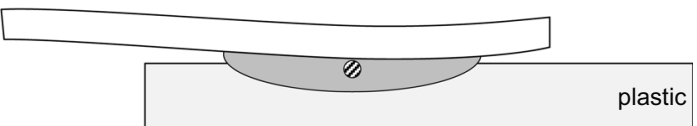

(3)

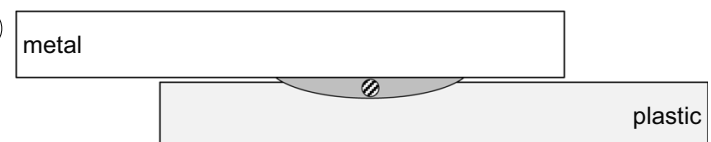

Fig. 14 FBGs data a for simultaneous welding, $\mathbf{b}$ temperature simulation data for different welding conditions and material thickness, and $\mathbf{c}$ calculated residual strains for simultaneous joining and comparison to the effects described 
$1 \mathrm{~mm}$ will theoretically result in a reduction of the temperature in the process zone, as shown by the simulations in Fig. 14b. However, the maximum $\Delta \lambda_{\mathrm{B}}$ from the FBGs for the sample with a welding time of $4 \mathrm{~s}$ and a metal thickness of $1 \mathrm{~mm}$ is much higher than for the sample with a welding time of $4 \mathrm{~s}$ and a plate thickness of $0.5 \mathrm{~mm}$. These counteracting effects can be explained by the calculation of the residual strains based on the shift of the peak wavelength after the welding process with respect to the initial wavelength $\Delta \lambda_{\mathrm{B}_{-} 0}$. On the one hand, the inherent strain increases with the increasing size of the melt zone, as given by joining times of 2 and $4 \mathrm{~s}$ at a constant sheet thickness of $0.5 \mathrm{~mm}$. This behavior was also observed for contour joining (see Sect. 3.2). On the other hand, distortion of the metal can also reduce the residual strain. This can be seen by comparing the results obtained from the sheet thicknesses of 0.5 and $1.0 \mathrm{~mm}$. Despite the lower volume of the molten material, an increased residual strain for $1.0 \mathrm{~mm}$ compared with $0.5 \mathrm{~mm}$ is detected. Owing to the increased material thickness and hence stiffness, no significant distortion occurs at $1.0 \mathrm{~mm}$, which is why the residual strain cannot be reduced through deformation.

A separation of the thermal and mechanical effects based on sensor signals will be pursued in the following. Assuming that the signal of FBGs is only a function of the process temperature (strain $=0)$, the temperature is calculated from the FBGs' data, with the thermal coefficient TC of $6.5 \cdot 10^{-6} \mathrm{~K}^{-1}$ according to the supplier, using the following equation:

$T=T_{\text {Ref }}+\frac{10^{6}}{\mathrm{TC}} \cdot \frac{\Delta \lambda_{\mathrm{B}}}{\lambda_{\mathrm{B} \_0}}$

Please note that the calculations are just for theoretical consideration and demonstrate the interplay between the different effects on the FBGs. The FBGs are directly embedded in the joint zone so that the temperature cannot simply be separated from the mechanical strain effects. For separating the temperature from the mechanical strain, the stress transfer from the joint to the FBGs must be hindered by encapsulation, which is practically impossible for the studied thermal-joining process.

However, for discussion of the influencing effects on the wavelength shift, the calculated temperature data versus time is compared with the temperatures of the simulations, indicated by the dashed line for each of the three data series in Fig. 15a. Deviations from the maximal temperature in the process and from room temperature after cooling are caused by actual mechanical and temperature strains near the FBG. With an increase in the temperature, deformation occurs and counteracts the maximum strains. On the other hand, the compression of the FBGs after cooling leads to negative strain. These effects are not compensated in the calculation, which is why the temperature curves show a deviation between the simulation and reality. In our study, the $\Delta \lambda_{\mathrm{B}}$ shift is mostly a result of the process temperature, of mechanically and thermally induced strains, as well as of the residual strains. The main effects are schematically shown in Fig. $15 \mathrm{~b}$ and demonstrate that further studies are necessary to fully understand the signal response in the process zoneembedded FBGs of laser-assisted thermal-joining processes. Based on the present study and the proof of principle of using FBGs in the process zone, future work will address the separation of temperature and strain effects which requires the mechanical decoupling of the sensor, for example, by encapsulation in tubes. This approach was not considered in this study to keep the influence of the fiber thickness in the process zone as small as possible. The development of ultra-thin fiber Bragg sensors (50 .. $80 \mu \mathrm{m}$ ) and micro-encapsulation techniques can contribute to the separation of temperature and strain in the future. Another new approach allows the separation of temperature and strain using polarization maintaining the optical fiber sensor. Hopf et al. show the applicability of this method for FBGs glued on the surface [6]. Especially important in this regard is the study of
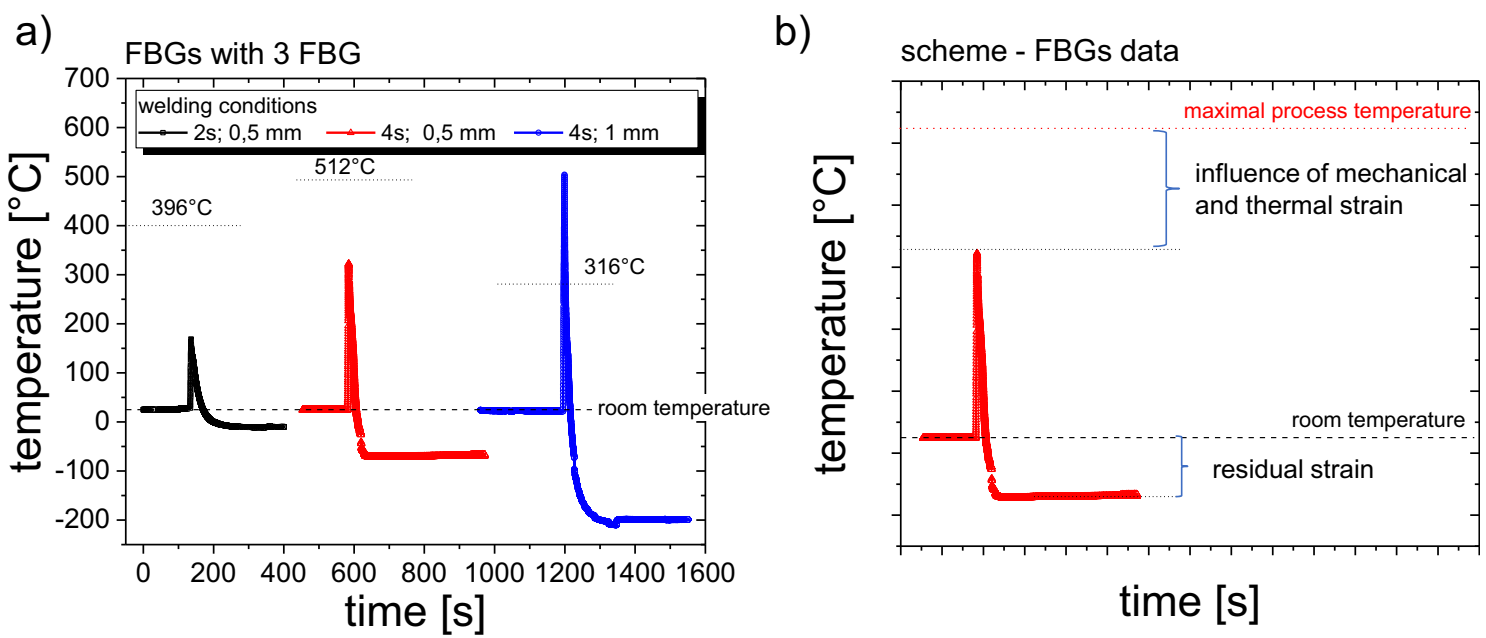

Fig. 15 Calculated temperature from FBGs data (a note: curves are shifted on $x$-axes for better visualization) and $\mathbf{b}$ scheme of possible influencing parameters 
resultant residual strains and stress, which can have a significant influence on the bonding strength of the joint.

\section{Summary and outlook}

Fiber Bragg grating sensors without a special metal coating have been successfully embedded in the joining zone of metal-polymer hybrids; they were used for process analysis during contour and simultaneous welding. The influence of clamping force, weld energy, and polymer material on the spectral response has shown significant effects on the spectra (peak shifting, distortion, splitting, broadening) resulting from process temperature and complex strain states during and after the welding. The course of the peak wavelength shift $\Delta \lambda_{\mathrm{B}}$ with process time can be directly correlated with specific events during welding and gives a qualitative impression of the temperature development directly in the process zone, as shown by the measurement of FBGs using polymer materials and different welding energies. The shift in the peak wavelength after welding and cooling gives a useful indication of the appearance of the residual strain experienced by the FBGs. Higher energy inputs in the joint result in higher residual strains. Thus, it has been demonstrated that FBGs offer significant potential for measuring temperature, temperatureinduced stains, and residual strains in the welding process.

Future investigations must consider the temperature compensations by using thinner encapsulated fiber sensors as well as new measuring techniques using polarization by maintaining fiber Bragg gratings in combination with numerical simulation of the welding process including residual strains. The combination of embedded sensors and simulation can provide a thorough understanding of the welding process of metal-polymer hybrids - this can also make the fiber Bragg grating approach a stable tool for the quality assurance and structural health monitoring of products made with the joining technology discussed in this paper.

Acknowledgements Open Access funding provided by Projekt DEAL.

Funding information The configuration of FBGs and the data evaluation of the sensors at the MFPA Weimar were realized in the FOS4FDM project of the Wachstumskern VIPO Virtuelle Produkt-/Prozessentwicklung und optimierung. M. Ganß thanks Bundesministerium für Bildung und Forschung (BMBF) for financial support. M. Ganß acknowledges Dr. E. Lindner and Dr. C. Voigtländer from FBGS Technologies $\mathrm{GmbH}$ for the great support and discussion on the draw-tower FBGs. The results were elaborated in part in the project "Production and Design Processes for the Efficient Manufacturing of Hybrid Components: Joining Process, Simulation, and Characterization" supported by the Free State of Thuringia (2016 FE 9077) and co-financed by European Union funds under the European Regional Development Fund (ERDF).

Open Access This article is licensed under a Creative Commons Attribution 4.0 International License, which permits use, sharing, adaptation, distribution and reproduction in any medium or format, as long as you give appropriate credit to the original author(s) and the source, provide a link to the Creative Commons licence, and indicate if changes were made. The images or other third party material in this article are included in the article's Creative Commons licence, unless indicated otherwise in a credit line to the material. If material is not included in the article's Creative Commons licence and your intended use is not permitted by statutory regulation or exceeds the permitted use, you will need to obtain permission directly from the copyright holder. To view a copy of this licence, visit http://creativecommons.org/licenses/by/4.0/.

\section{References}

1. FBGS: Draw Tower Gratings (DTG®). Internet: https://FBGs.com/ components/draw-tower-gratings-dtgs/. Accessed on 03 Jul 2019

2. Ganß M, Barnickel J, Kuhne M, Beinersdorf H, Hildebrand J, Bergmann JP, Könke C (2017) Zustandserfassung von strukturellen Klebverbindungen mittels faseroptischen Sensoren: Untersuchungen an geklebten Stahl-CFK-Verbindungen, in Smarte Strukturen und Systeme, p. 51, Tagungsband des 4Smarts-Symposium. ISBN: 978-3-8440-5083-7

3. Grandal T, Fraga S, Castro G, Vazquez E, Zornoza A (2017) Fibre optic sensor embedded into metals using low cost TIG welding and high precision laser brazing

4. Hadzic R, John S, Herszberg I (1999) Structural integrity analysis of embedded optical fibres in composite structures. Compos Struct 47(1-4):759-765

5. Heckert A, Singer C, Zaeh MF, Daub R, Zeilinger T (2016) Gastight thermally joined metal-thermoplastic connections by pulsed laser surface pre-treatment. Phys Procedia 83:1083-1093

6. Hopf B, Fischer B, Bosselmann T, Koch AW, Roths J (2019) Strain-independent temperature measurements with surface-glued polarization-maintaining fiber Bragg grating sensor elements. Sensors 19:144. https://doi.org/10.3390/s19010144

7. Kohl M-L, Schricker K, Bergmann JP, Lohse M, Hertel M, Füssel U (2018) Thermal joining of thermoplastics to metals: surface preparation of steel based on laser radiation and tungsten inert gas arc process. Procedia CIRP 74:500-505

8. Kuang KSC, Kenny R, Whelan MP, Cantwell WJ, Chalker PR (2001) Embedded fibre Bragg grating sensors in advanced composite materials. Compos Sci Technol 61:1379-1387

9. Lambiase F, Genna S (2017) Laser-assisted direct joining of AISI304 stainless steel with polycarbonate sheets: thermal analysis, mechanical characterization, and bonds morphology. Opt Laser Technol 88:205-214

10. Levesque D, Legros A, Michel A, Piche L (2012) High resolution ultrasonic interferometry for quantitative nondestructive characterization of interfacial adhesion in multilayer (metal/polymer/metal) composites. J Adhes Sci Technol 7:719-741

11. Lindner E (2012) Erzeugung und Eigenschaften hochtemperaturstabiler Faser-Bragg-Gitter. PhD thesis, FriedrichSchiller-University Jena, Jena

12. Moreira PMGP, Frazao O, Tavares SMO, de Figueiredo MAV, Restivo MT, Santos JL, de Castro PMST (2007) Temperature field acquisition during gas metal arc welding using thermocouples, thermography and fibre Bragg grating sensors. Measurement Science and Technology 18(3)

13. Müller M, Hoffmann L, Lautenschlager T, Koch A (2008) Soldering fiber Bragg grating sensors for strain measurement. Proc SPIE Int Soc Opt Eng. https://doi.org/10.1117/12.786088

14. Park C, Peters K (2012) Comparison of damage measures based on fiber Bragg grating spectra. Meas Sci Technol 23(2):025105,13

15. Peters K, Studer M, Botsis J, Iocco A, Limberger H, Salathe R (2001) Embedded optical fiber Bragg grating sensor in a 
nonuniform strainfield: measurements and simulations. Exp Mech 41(1):19-28

16. Peters K (2009) Chapter 61, S. 1103. Fibre Bragg Gratings Sensors. In: Boller C, Chang F-K, Fujino Y (eds) Encyclopedia of structural health monitoring, vol 2. Wiley

17. Richards WL, Parker AR, Ko WL, Piazza A, Chan P (2012) Application of fiber optic instrumentation, RTO AGARDograph 160 , flight test instrumentation series 22, ISBN 978-92-837-0164-4

18. Richter-Trummer V, Silva SO, Peixoto DFC, Frazão O, Moreira PMGP, Santos JL, de Castro PMST (2010) Fibre Bragg grating sensors for monitoring the metal inert gas and friction stir welding processes. Meas Sci Technol 21:8

19. Rodriguez-Cobo L, Mirapeix J, Ruiz-Lombera R, Cobo A, LópezHiguera J (2013) Fiber Bragg grating sensors for on-line welding diagnostics. Proc. SPIE 8794, Fifth European Workshop on Optical Fibre Sensors, 879441

20. Schroeder K, Ecke W, Apitz J, Lembke E, Lenschow G (2006) Fibre Bragg grating sensor system monitors operational load in a wind turbine rotor blade. Meas Sci Technol 17:1167-1172

21. Schmitt R, Mallmann G, Ackermann P, Bergmann JP, Stambke M, Schricker K (2015) 3D weld seam characterization based on optical coherence tomography for laser-based thermal joining of thermoplastics to metals. Lasers in Manufacturing Conference 2015, 8 p

22. Schricker K, Stambke M, Bergmann JP (2015) Experimental investigations and modeling of the melting layer in polymer-metal hybrid structures. Weld World 59:407-412

23. Schricker K (2018) Charakterisierung der Fügezone von laserbasiert gefügten Hybridverbunden aus teilkristallinen thermoplastischen Kunststoffen und Metallen. Technische Universität Ilmenau, $\mathrm{PhD}$ thesis

24. Technica Optical Components: T25/gold coated FBG with hermetic seal. Internet: https://technicasa.com/t25-gold-coated-fbghermetic-seal/. Accessed 03 Jul 2019

25. Voet E (2010) In-situ deformation monitoring of aerospace qualified composites with embedded improved draw tower fibre Bragg gratings, $\mathrm{PhD}$ thesis, Gent

26. Zhou Z, Graver TW, Hsu L, Ou J (2003) Techniques of advanced FBG sensors: fabrication, demodulation, encapsulation and the structural health monitoring of bridges. Pacific Sci Rev 5:116

Publisher's note Springer Nature remains neutral with regard to jurisdictional claims in published maps and institutional affiliations. 